\title{
A alimentação orgânica e as ações educativas na escola: diagnóstico para a educação em saúde e nutrição
}

\author{
Organic food and educational actions in schools: \\ diagnosis for health and nutrition education
}

\author{
Elisângela da Cunha ${ }^{1}$ \\ Anete Araújo de Sousa ${ }^{1}$ \\ N eila M aria Viçosa M achado ${ }^{2}$
}

IPrograma de Pósgraduação em Nutrição, UniversidadeFederal de

Santa Catarina. Caixa Postal

476, Campus Universitário

Trindade. 88040-900

Florianópolis SC.

sansacunha@yahoo.com.br

${ }^{2}$ Departamento de N utrição,

Programa de Residência

Integrada em Saúdeda

Família. Universidade

Federal deSanta Catarina.
Abstract This research involved a diagnosis of the educational actions and organic food of the Taste and Awareness Project (Projeto Sabor e Saber, PSS) in a state school in Florianopolis, Brazil. Based on a qualitative approach, a semistructured interview, documentation analysisand focal groups were used for data collection. The participants were managers of School M eals; a school head and a group of students and teachers representing theschool. Theresultsindicated that the PSS has advanced in its objectives, combining the introduction of organic foods with educational actions involving food, health, nutrition and the environment but with no evaluations of this process; organic food is present in school meals, although there is no record of educational actions; food is a subject on the Science course; the themes of food, health and nutrition in the school environment comeup without planning; theevaluation of students regarding the food is positive, but no reference was made to organic foods. It was concluded that the use of organic food, is still not an element of the pedagogical project. However, the research contributed to the teachers, on the need to devel op educational actions in health, organic foods and nutrition, within the school community.

Key words School meals, Health and nutrition education, Educational actions, Organic foods, Qualitative research, Focal groups
Resumo A pesquisa envolveu um diagnóstico das ações educativas e alimentação orgânica do Projeto Sabor Saber (PSS) em uma escola estadual em Florianópolis, Brasil. A partir de uma abordagem qualitativa, utilizou a entrevista semi-estruturada, a análise documental eos gruposfocais para a coleta de dados. Participaram da pesquisa: gerente da alimentação escolar, diretora, grupo de escolarese professores da escola. Os resultados evidenciaram que o PSS avançou em seus objetivos, aliando introdução dealimentosorgânicosa ações educativas em alimentação, saúde, nutrição emeio ambiente, mas sem avaliações sobre este processo. 0 alimento orgânico está presente na alimentação escolar; contudo, não há regi stro de ações de educação em saúde e nutrição. A alimentação é conteúdo na disciplina de Ciências; todavia, os temas alimentação, saúde e nutrição surgem sem planejamento prévio. A avaliação dos escolares sobre a alimentação é positiva; porém, os alimentos orgânicos não foram referidos. Concluiu-se que a utilização do alimento orgânico ainda não integra o projeto pedagógico desta escola; no entanto, os professores refletiram sobre a necessidade do desenvolvimento de ações de educação em saúde, alimentação orgânica e nutrição com a comunidade escolar.

Palavras-chave Alimentação escolar, Educação em saúde e nutrição, Ações educativas, Alimentação orgânica, Pesquisa qualitativa, Grupos focais 
Introdução

O Programa Nacional de Alimentação Escolar (PNAE), gerenciado pelo Fundo Nacional de Desenvolvimento da Educação (FNDE), tem como objetivos a melhoria das condições nutricionais, a contribuição para a aprendizagem e o rendimento escolar dos estudantes, bem como a formação de hábitos alimentares saudáveis ${ }^{1}$.

Dentro desta abordagem, o PNAE surge como possibilidade para o redimensionamento das ações desenvolvidas na escola, podendo ter um papel estratégico para mudanças das práticas al imentares dos escolares. Pode ainda contribuir com a promoção da educação em saúde e nutrição, contextualizando as práticas de educação nutricional numa perspectiva mais ampla de construção da cidadania ${ }^{2-5}$.

Desta forma, diferentes experiências brasileiras no âmbi to da escola vêm se solidificando com base na proposta de iniciativa das Escolas Promotoras de Saúde. Esta proposta, com o aval da Organização Pan-Americana de Saúde (OPAS), busca pautar práticas fomentando o desenvolvimento humano saudável com relações humanas construtivas eharmônicas, promovendo aptidões e atitudes positivas para a saúde. É também reconhecida pelo desenvolvimento de ações que possibilitam ampliar, de forma significativa, os papéis da alimentação escolar para a promoção da educação em saúde e nutrição ${ }^{6}$.

N esta perspectiva, em Santa Catarina, um convênio entre a Secretaria de Estado da Educação, Ciência e Tecnologia (SED) e a Associação dos Agricultores Ecológicos da Encosta da Serra Geral (AGRECO) permitiu a operacionalização do Projeto Sabor Saber, que beneficia escolas básicas da rede estadual de ensino de Florianópolis e outros municípios do estado com a alimentação escolar orgânica. 0 Projeto Sabor Saber tem como objetivo central a implantação gradativa, dentro do Projeto Político Pedagógico de cada escola da rede pública estadual, do Projeto Escolar de Alimentação Orgânica (PEAO). 0 PEAO busca promover a formação de bons hábitos alimentares, elevando a qualidade das re feições servidas no Programa Estadual de Alimentação Escolar, em todas as unidades escolares da rede, através da introdução de alimentos orgânicos nos cardápios ${ }^{7}$.

Ressalta-se que o conceito de sistema orgânico de produção agropecuária está contemplado na Lei 10.831, de 2003, do M inistério da Agricultura, Pecuária eAbastecimento, queo define como todo aquele em que se adotam técnicas específi- cas, mediante a otimização do uso dos recursos naturais e socioeconômicos disponíveis e o respeito à integridade cultural das comunidades rurais, tendo por objetivo a sustentabilidadeeconômica eecológica, a maximização dos ben efícios sociais, a minimização da depen dência deenergia não-renovável, empregando, sempreque possível, métodos culturais, biológicos e mecânicos, em contraposição ao uso de materiais sintéticos, a eliminação do uso deorganismos geneticamente modificados e radiações ionizantes, em qualquer fase do processo de produção, processamento, armazenamento, distribuição e comercialização, e a proteção do meio ambiente . $^{\text {. }}$

D estaca-se que a agricultura orgânica surgiu no Brasil na década de setenta; porém, a partir dos anos oitenta, com o crescimento da conscientização da necessidade de preservação ecológica, ocorreu a expansão da clientela dos alimentos oriundos do sistema de produção orgânica. N esta fase, organizaram-se muitas das cooperativas destetipo de produção hoje em atividade, a exemplo da AGREC ${ }^{9,10}$.

O Projeto Sabor Saber atende 155 escolas públicas do Estado de Santa Catarina e tem como premissa que, ao introduzir a alimentação orgânica no Projeto Político Pedagógico das escolas, considerando o seu caráter educativo, econômico, político e social, pode ultrapassar a visão de manutenção da condição deintegridadefisiológica do escolar ou ainda de repasse de alimentos ${ }^{7}$.

Salienta-se que a utilização do alimento orgânico como um dos elementos do projeto pedagógico pode abrir possibilidades denovas abordagens educativas para estudantes, professores e dirigentes. Ações desta natureza têm sustentação nas Diretrizes dos Parâmetros Curriculares Nacionais (PCN) do Ministério da Educação ${ }^{11}$, na Estratégia Global para Alimentação Saudável, Atividade Física e Saúde da Organização M undial da Saúde ${ }^{12}$, nas recomendações da Portaria Interministerial no 1.010 de 8 de maio de 2006, que instituem diretrizes para Promoção da Alimentação Saudável nas escolas de educação infantil, fundamental e nível médio das redes públicas e privadas ${ }^{13}$ e nas já citadas perspectivas das Escolas Promotoras de Saúde da OPAS ${ }^{6}$.

Diante destas considerações, a presente pesquisa envolveu um diagnóstico das ações deeducação em saúde e nutrição com base na alimentação orgânica em uma unidade escolar do Estado de Santa Catarina. Teve como propósito contribuir com elementos para avaliação do Projeto Sabor Saber e ainda incorporar uma discussão sobre saúde, alimentação escolar e alimentação 
orgânica, avaliando o engajamento de participantes da escola.

\section{Percurso metodológico}

A pesquisa apresentou a metodologia qualitativa como modelo deabordagem. A definição desta base metodológica é explicada devido à natureza do estudo proposto: a pesquisa qualitativa preocupa-se com um nível de realidade que não pode ser quantificado; 0 fenômeno a ser estudado pode ser mais bem compreendido no contexto em que ocorre e do qual é parte, devendo ser analisado numa perspectiva integrada; as estruturas e instituições são vistas como resultado da ação humana objetivada ${ }^{14,15}$.

O campo de análise, como explicitado, compreendeu uma escola de ensino fundamental exclusivo ( $100 \%$ beneficiada pelo PN AE), referência nautilização dealimentos orgânicos e sede de vários projetos educacionais desenvolvidos no Estado e pioneira na implantação do Projeto Sabor Saber junto à Secretaria de Estado da Educação de Santa Catarina (SED). A escola atende, aproximadamente, trezentas crianças, divididas em doze turmas, entre a préescola e o ensino fundamental.

A pesquisa foi desenvolvida no período de agosto a dezembro de 2006. Participaram da pesquisa a gerente de alimentação escolar, a nutricionista responsável pela alimentação escolar, uma educadora participante da elaboração e desenvolvimento do Projeto Sabor Saber, a diretora, a assistente, a orientadora pedagógica e a coordenadora da escola, professores e escolares.

0 referencial teórico ${ }^{16-21}$ possibilitou a elaboração do modelo de análise culminando nas seguintes categorias e subcategorias:

a. Avaliação do Projeto Sabor Saber em relação às diretrizes e aos objetivos do Programa Nacional de Alimentação Escolar (PNAE): dire trizes e objetivos do PNAE; diretrizes e objetivos do Projeto Sabor Saber (indicadores de avaliação e alcance dos objetivos);

b. Ações e estratégias educativas em saúde e nutrição ea alimentação orgânica: ações de educação em saúde e nutrição (características das ações edu cativas com os alimentos orgânicos por disciplinas e por projetos); ambiente da escola (espaços pedagógicos e recursos utilizados);

c. A alimentação orgânica no Projeto Político Pedagógico (PPP): temas transversais (relação dos temas transversais no PPP e localização da alimentação nos temas transversais); estratégias para o desenvolvimento da alimentação/alimentos orgânicos e planejamento anual das atividades (alimentos ealimentação orgânica nas disciplinas, nos projetos, na programação de atividades individuais e/ ou grupais).

Cada uma das categorias orientou a elaboração de perguntas-guias, relativamente abertas, utilizando-se como técnica de abordagem a entrevista semi-estruturada. Os participantes foram entrevistados respeitando-se os seus próprios quadros de referência - a sua linguagem e as suas categorias mentais-, mas, ao mesmo tempo, encaminhando-os para os objetivos da pesquisa, de forma natural ${ }^{22}$. As entrevistas foram realizadas através de encontros com profissionais em seus contextos de trabalho. Os dados foram registrados em um gravador e/ou caderno-diário, cujas anotações foram realizadas durante ou imediatamente após os encontros.

A análise documental foi utilizada como recurso para conhecimento dos relatórios referentes às atividades educacionais envolvendo o PSS, do planejamento anual deatividades escolares, dos projetos que envolvem saúde e alimentação na escola, bem como dos planos de ensino disponíveis das diferentes áreas do conhecimento do PPP.

Além destas técnicas, a partir da questão norteadora "Como você avalia a alimentação oferecida pela escola?", utilizou-sea técnica dos grupos focais com professores e escolares para compreender as concepções sobre saúde, al imentação escolar e alimentação orgânica na escola. 0 grupo focal é uma técnica de coleta de dados inspirada em entrevistas utilizadas na psiquiatria ${ }^{23,24}$. Consiste em entrevistas em grupo, sobre um tema específico, e busca colher informações que possam proporcionar a compreensão de percepções, crenças, atitudes sobre um tema, produto ou serviço, baseando-se na interação entre as pessoas ${ }^{23}$.

A técnica de grupo focal utiliza a interação grupal para a produção de insights que dificilmente seriam conseguidos fora do grupo ${ }^{24}$. Esta técnica vem sendo amplamente utilizada na pesquisa qualitativa, pois, ao mesmo tempo em que permite ao pesquisador obter dados para seus estudos, garante aos pesquisados um espaço de reflexão desuas próprias concepções euma autoavaliação.

Os grupos focais envolveram sete docentes e vinte escolares representantes das turmas de 1 a a 7 ạ séries, escolhidos aleatoriamente pel os professores e divididos em dois grupos focais.

Da mesma forma, os professores que participaram da pesquisa foram divididos em dois grupos. 
Os quatro encontros transcorreram dentro do espaço físico da escola com duração média de uma hora evinte minutos. Os grupos focais com os escolares foram acrescidos de dinâmica com desenho ${ }^{25}$.

Foram distribuídos canetas coloridas, giz de cera e folhas de papel branco para desenvolvimento da dinâmica, instruindo-os, individualmente, a representarem sua avaliação sobre a alimentação oferecida na escola. Posteriormente, cada escolar foi convidado a explanar sobre significado de seu desenho.

Osdados obtidosa partir das entrevistas eanálise documental foram descritos e analisados com o auxílio do referencial teórico utilizado na construção do modelo de análise 22 , além de outros referenciais que pudessem auxiliar na discussão dos dados. As concepções e os conceitos que surgiram com o desenvolvimento dos grupos focais foram categorizados e analisados, seguindo à técnica de análise de conteúdo proposta por Bardin ${ }^{26}$.

0 projeto de pesquisa foi apreciado e aprovado pelo ComitêdeÉtica de Pesquisa com Seres Humanos (CEPSH) da Universidade Federal de Santa Catarina (UFSC), e os participantes assinaram o termo de consentimento livre e esclare cido. Para garantia do anonimato das pessoas que participaram da pesquisa, estas foram citadas por cognomes.

\section{Resultados ediscussão}

O Projeto Sabor Saber (PSS) em relação às diretrizes e aos objetivos do Programa Nacional de Alimentação Escolar (PNAE)

O PNAE tem como objetivo oferecer um aporte de nutrientes e uma alimentação adequada durante o período em que o estudante está na escola. A melhoria das condições fisiológicas do aluno, de forma a contribuir para o seu desenvolvimento escolar, é apontada como uma premissa do programa.

Observou-se uma visão ampliada sobre 0 papel do PNAE entre os profissionais que integram a gerência de alimentação escolar de Santa Catarina ao argumentarem que 0 Programa (PNAE) não tem o objetivo de tratar obesidade ou desnutrição, mas o equilíbrio da alimentação (Ana/ Gerência). Hoje o programa é sobre a alimentação, educação nutricional e formação de bons hábitos ( $M$ aria/Gerência).

Defato, entre as diretrizes do PNAE, ganharam destaque a necessidade de implementação da educação alimentar enutricional no processo ensino-aprendizagem e 0 imperativo de que estas ações perpassem transversalmente pelo currículo escolar ${ }^{27}$.

Outro aspecto importante foi a introdução do conceito deal imentação saudável considerando-a como direito humano, envolvendo aspectos alimentares que garantam condições biológicas, sociais e culturais dos indivíduos, de acordo com as fases do curso da vida e com base em práticas alimentares que assumam os significados socioculturais dos alimentos ${ }^{13}$.

Contudo, Bezerra ${ }^{16}$ e M ainard ${ }^{17}$ ressaltam que ainda é atribuído à alimentação escolar 0 alento para solução dos problemas nutricionais e de aprendizagem. Desta forma, a escola e as estruturas socioeconômicas, ao tomarem conceitos e explicações do campo da saúde, ficam liberadas do contexto social.

Os profissionais da gerência de alimentação escolar também apontam os limites da concepção do papel da alimentação escolar, salientando que o PNAE no Estado de Santa Catarina continua um programa assistencial, em escolas públicas com alunos mais carentes, evitando evasões. Traz alunos para as aulas (Ana/Gerência).

0 aspecto assistencialista das políticas e programas vigentes ainda é uma realidade, principalmente devido às desigualdades sociais e econômicas do país. Esta observação é destacada no Programa Estadual de Alimentação Escolar da Secretaria de Estado da Educação, Ciência e Tecnologia de Santa Catarina (SED) quando refere que a alimentação escolar, como uma política educacional, está presente nas preocupações daqueles que se dedicam a estudar as condições de escolaridade, mas não ocupa papel relevante na preocupação dos educadores em geral ${ }^{28}$.

Contudo, mesmo diante desta condição, Bezerra ${ }^{16}$ argumenta que a alimentação escolar na prática ou como política social tem uma dimensão dialética, podendo ser considerada um instrumento de criação de possibilidades de emancipação. A oferta da alimentação aos escolares, mesmo que parcialmente, pode contribuir para que tenham melhor predisposição para aprender. Desta forma, ao se instrumentalizarem via saber sistematizado, e conscientizando-se de sua realidade, podem desenvolver um agir crítico e transformador ${ }^{3}$.

Em seu texto, o Projeto Escolar deAlimentação O rgânica (PEAO) destaca que a alimentação escolar, além do aspecto nutricional, envolvetambém o processo ensino-aprendizagem que, permeado pelos aspectos sociais, deve ser trabalha- 
do na escola, proporcionando possibilidades de avanço na caminhada para uma vida mais justa e saudável aos educandos e à comunidade escolar em geral ${ }^{7}$.

Ressalta-se que o caráter educacional da alimentação na escola é reconhecido pela gerência de alimentação escolar do Estado de Santa Catarina ao envolver nutricionista, pessoal da área administrativa e da área da educação na participação da elaboração e assessoria nas escolas para implantação de projetos educacionais relacionados à alimentação. A este respeito, Ribei ro ${ }^{29} \mathrm{de}$ fende a necessidade de uma abordagem multidisciplinar deste tema para que as experiências tenham êxito e envolvam, de fato, a educação em saúde e nutrição.

O PSS teve seu início em sessenta escolas e atende hoje a mais de 150 instituições. M esmo com propósitos educativos desde a sua implantação, ainda não há avaliação sobre aspectos educacionais, indicadores de saúde e sociais, conforme relato dos profissionais da gerência da alimentação escolar: Em 2003, existiam sessenta escolas vinculadas ao programa de consumo de alimentos orgânicos, mas não existia nenhum projeto pedagógico disto, nenhum vínculo, era apenas merenda. A alimentação orgânica não era conhecida pelos pais das crianças, e aí surgiu o Sabor Saber (M aria/Gerência). É difícil atribuir ao programa as variáveis de aprendizado, não é objetivo do programa medir isso. 0 sabor e apresentação também não têm sido verificados quanto à prefe rência. Só o aumento deconsumo defolhosos, maior variedade, queforam observados (Ana/ Gerência). Não [há avaliação], mas o propósito é de medir isso durante esse ano. 0 programa contribui para melhorar a alimentação, mas não foram medidos os resultados para a saúde das crianças (Flor/Gerência). A gricultores vivem de vender os al imentos para a alimentação escolar, também melhoram sua renda, eela torna-se garantida. N os outros pontos, os dados são empíricos (Flor/ Gerência). N ão existenenhuma avaliação do programa, o que existem são controles financeiros (M aria/ Gerência).

Considera-se que, em se tratando de um projeto dealimentação queutiliza o al imento orgânico eapresenta objetivo social e educativo ampliados, a necessidade de acompanhamento éfundamental para avaliação e aperfeiçoamento, bem como a socialização dos resultados do projeto.

É fato que, com as constantes reformulações, - PNAE, no Brasil, tem avançado em seus objetivos. Dentre estes, se destacam as recomendações acerca da necessidade de estímulo de hábitos alimentares saudáveis no âmbito escolar e a in- corporação do tema alimentação saudável ao projeto político pedagógico da escola, de forma transversal, propiciando experiências no cotidiano das atividades escolares ${ }^{27}$.

Para os profissionais responsáveis pelo desenvolvimento e implantação do Projeto Sabor Saber, estas recomen dações ainda não estão presentes nas escolas: H oje o real é o alimento orgânico na escola, mas os alunos não têm consciência disso, não há participação pedagógica, não há trabalho em sala de aula. Embora não se alcance 0 trabal ho em sala deaula, 0 oferecimento desses alimentosjá é educacional (Ana/Gerência).

M ogilka ${ }^{21}$ argumenta que é preciso superar a idéia, ainda presente na educação escolar, que a realização de atividades propostas já caracteriza efeitos educativos e sociais. Parece que a atividade em si não necessariamente gera mudanças subjetivas, apesar das reflexões advindas destas atividades einterações.

Além disso, a teoria e a prática da formação devem contemplar todos os aspectos do ato educativo, para que este se dê de forma integral. Estes aspectos são relevantes para formação da consciência do coletivo escolar na construção de um cidadão crítico e agente de mudanças ${ }^{21}$.

Ações e estratégias educativas em saúde e nutrição e a alimentação orgânica no projeto político pedagógico da escola

No projeto político pedagógico (PPP), concluído em 2005, os temas saúde, alimentação e nutrição são apontados em algumas disciplinas. No entanto, não ficam claras a transversalidade e a interdisciplinaridade destes temas. A coordenação educacional da escola encontra também dificuldades em ampliar o número de profissionais em seu corpo docente que abracem a proposta de sistematização das atividades educativas, inclusive daquelas que envolvam a alimentação orgânica.

Segundo Bezerra ${ }^{16}$, há um desinteresse dos educadores e pedagogos pelo tema alimentação escolar. No levantamento bibliográfico, realizado em seu estudo, constatou que os trabalhos nesta área são desenvolvidos por engenheiros de alimentos, nutricionistas, médicos e psicólogos.

Além disso, estudos revelam que um grande número de escolas públicas parece não atentar para a importância da sistematização e avaliação dos trabalhos pedagógicos. Há, por vezes, uma negação do processo reflexivo. Todavia, a construção de forma col etiva do PPP pode contribuir para a formulação de um mecanismo democrá- 
tico de organização e dinamização das ações educativas no espaço pedagógico 30,31.

A direção da escola apresentou dificuldade em apontar atividades pedagógicas curriculares, desenvolvidas com o tema alimentação orgânica: A escola sente falta de esclarecimento teórico para professores e alunos [sobre al imentos orgânicos]. A escola corre atrás destas informações. 0 alimento orgânico não está sendo trabalhado em sala. Não está escrito dentro do plano de ensino que na disciplina tal irá se falar sobre os orgânicos, mas se el es vão falar dealimentoseusam os orgânicos como caminho, depende decada professor (Cristal/Direção da escola). Assim, nos planos de ensino, o tema alimento orgânico não aparece como ponto a ser trabalhado nas e entre as disciplinas.

Alimento orgânico, saúde e nutrição:

com a palavra, os professores e escolares

Os professores relataram que os temas alimentação e utilização do produto de origem orgânica na alimentação escolar são abordados em sala de aula e destacaram que os escolares tinham consciência da presença destes produtos diferenciados na alimentação escolar: A gentefala da importância dos alimentos, a gente fala da merenda, da qualidade dos alimentos aqui, que é uma das melhores (Prof 1). Eu acho que foi trabalhado bas tante [ o tema alimentação escolar orgânica], conversado com 0 aluno. Para ter o resultado que te mos? M esmo que não sistematizado esse esclarecimento, eu acho quefoi feito com sucesso (Prof 3). A hora da alimentação é maravilhosa. 0 que a gente faz é incentivar, porque sabe como é criança, a maioria não gosta desalada eeles comem, tem variedademuito grande. A nossa contribuição está aqui, a gente explica sobre saúde, o que é mais barato, da época, onde são produzidos (Prof 1). Sempre comento com alunos sobre a importância de comer frutas e verduras, e com frequência eles me perguntam se faço dieta, pois têm essa concepção (Prof 2).

Alguns professores transformam as informações sobre alimentação em temas para os escolares dentro e fora de sala de aula: Converso constantemente com alunos porque eles perguntam por que não podem comprar alimentos no barzinho, por que não tem cantina? Então eu explico aos alunos que existe uma lei, e também porqueéuma concepção da escola, que é contra os alimentos ricos em gordura, frituras, processados, e opta por uma alimentação mais equilibrada (Prof 2).

Santo $^{32}$ defende a inclusão dos temas que envolvem a educação em saúde e nutrição nos projetos pedagógicos dos diferentes níveis deen- sino para favorecer aos sujeitos a criticidade das informações que circulam. Ainda considera importante abordar estes temas nas discussões político-filosóficas do ensino brasileiro, não os reduzindo à mera inclusão de conteúdos.

Destaca-se que a dificuldade de sistematização dos conteúdos sobre alimentação, ultrapassando o que está proposto pelo livro didático, foi levantada pelos professores. Conforme relatado pela direção da escola, há carência de informações teóricas para professores trabalharem com este tema. Davanço et al.$^{33}$, ao avaliarem os conhecimentos sobre nutrição de professores expostos e não expostos a um programa educativo, concluíram que os professores expostos ao programa se apresentaram mais preparados conceitual mentee mais sensibilizadosquanto ao seu papel e da escola como formadores e transformadores de hábitos de saúde e nutrição.

Porém, éfato que a dimensão saúde, alimentação e nutrição como conhecimento ainda não está alcançando a relevância proposta pelos gestores federais e estaduais. A necessidade de ações educativas com professores para que os programas de saúde e nutrição possam obter algum êxito é discutida por Davanço et al. ${ }^{33} \mathrm{eG}$ aglianone et al. ${ }^{34}$. Estas atividades necessitam de continuidade, pois se trata de um processo em que os resultados não surgem em curto prazo.

$\mathrm{Na}$ escola, a abordagem dos assuntos saúde, alimentação, alimentos orgânicos e nutrição, ministrada aos escolares de 5a a 8a séries, são de responsabilidade da disciplina de Ciências. Além do livro didático, são utilizadas como estratégias de ensino-aprendizagem: visitas, pesquisas na horta escolar e estímulo ao cultivo domiciliar de temperos, conforme destacado por um professor: A questão dos alimentos é falada em todas as séries, porém com ênfase na sétima série ( partes do corpo esistema digestório). Na quinta série, quando entra no conteúdo quefala sobreraízes das plantas, levam-se as crianças para horta (Prof 5).

Para os escolares de 1a a 4ํa séries, os alimentos são, eventualmente, utilizados no processo pedagógico. Contudo, as atividades parecem ter sua abordagem prejudicada. A horta da escola não é utilizada pelos escolares destas séries, justificado pela pequena área existente. Vale ressaltar que, além das inúmeras possibilidades didáticas que podem ser desenvolvidas na horta escolar, este ambiente é apontado como umas das estratégias a serem estimuladas para promoção de uma alimentação equilibrada, modos de vida saudáveise a prevenção de distúrbios alimentares e doenças relacionadas à alimentação inadequada ${ }^{1,18,27}$. 
Os professores relataram exemplos de formas de trabalho utilizadas, em que foram criados ambientes como parte do processo pedagógico: um mercado em sala de aula, onde os escolares trabalharam informações de todas as áreas, e a feira de ciências, queé desenvolvida em conjunto com várias escolas. Porém, os professores consideraram que a feira de ciênciasfica pouco contextualizada quando não aconteceno espaço onde a criança tem seu cotidiano de aprendizado.

Constatou-se que os grupos focais fomentaram nos professores um ol har diferenciado acerca das possibilidades, além da horta, de se fazer educação em saúde e nutrição nos diversos espaços da escola, usando o alimento como meio pedagógico, conforme os relatos: Ano passado houve atividade com alunos dentro da cozinha, em pequenos grupos, eles produziram pães e outras preparações. Foi bacana! Até hoje el es perguntam: quando é que vai ter de novo professora? (Prof 5). 0 lancheéum momento de aprendizado sobrealimentos, ultimamenteas crianças têm comido muito mais fol has, verduras. 0 ato de sentar à mesa, ter refei ção, usar tal heres e a convivência entre crianças surgem como um momento rico, de aprendizado, de estímulo a uma boa alimentação (Prof 2).

Porém, Ribeiro ${ }^{29}$ e Davanço et al. ${ }^{33}$ reforçam a necessidade de aproximações científicas de e entre conhecimentos diversos, em que se possa conjugar o senso comum e a ciência, buscando bem mais a formulação de novas perguntas do quea acumulação de respostas duradouras. Deixar de contemplar as ciências positivas em busca de leis e voltar para as ciências interpretativas a procura de significados.

Esse movimento trouxe, ainda, a constatação da importância da abordagem interdisciplinar sobre alimentação e a necessidade de planejamento das ações: Há a necessidade deum planejamento conjunto, para que os temas que envolvam alimentação não fiquem só com Ciências. Por exemplo, a disciplina de $M$ atemática vai medir a cerca da horta e só? É necessário um planejamento para mais atividades nesseespaço (Prof 2). Eu acho que a gente tinha de ter um momento, usando a alimentação escolar para quea gentepudessesistematizar e fazer uma feira, uma oficina. Está faltando sistematizar. Nós temos que dar um jeito de trabalhar em todas as disciplinas isso, fazer momento único de trabalho por todos os professores (Prof 2). Então, mas eu acho que a gente podia planejar duas vezes ao mês ou uma vez por semana cada, para cada turma receber os alimentos orgânicos (Prof. 2). Toda terça-feira uma turma receberia os alimentos (Prof 6). N ós somos dezesseis.
Se cada professor pensar...(Prof 5). Vamos pensar, é discussão (Crista/Direção).

$\mathrm{Na}$ escola, com a publicação dos Parâmetros Curriculares $\mathrm{N}$ acionais, a proposta é de que a formação dos estudantes tenha um caráter mais geral, possibilitando-Ihes exercitar sua capacidade de buscar informações e analisá-las de forma significativa, deixando de lado o hábito da memorização. Porém, a metodologia interdisciplinar prevêa integração de áreas diferentes, necessita de um tempo maior de diálogo entreosmembros do grupo, educador e educando, mais disponibilidade para aceitar a diferença e para conhecer as contribuições que cada disciplina pode dar na construção ou na reconstrução de um conhecimento contextualizado ${ }^{11,19,21}$.

A sensibilização dos professores sobre seu papel de facilitador na construção dos temas sobre saúde, alimentação e nutrição através de metodologias integradoras parece ser um dos caminhos para que estes conhecimentos possam fazer parte da estrutura curricular básica da escola $a^{33,34}$.

Como aliado, o Programa de Alimentação Escolar pode tornar-se um espaço favorável à aprendizagem, como um processo social e permanente, para que todos aqueles que exercem suas atividades neste cenário possam conduzir sua alimentação para uma vida mais saudável, cientes dos limites e possibilidades de suas práticas alimentares ${ }^{1,3,5,6,11,13,22,24}$.

Destaca-se ainda que a promoção à saúde eà educação como um processo ativo do indivíduo, considerando seu conhecimento, possibilita às pessoas a ascensão como ser e cidadão. A alimentação escolar pode ser considerada um instrumento pedagógico para promoção da saúde e nutrição, contextualizando as práticas de educação nutricional numa perspectiva mais ampla de construção da cidadania $a^{3,35}$, ultrapassando, inclusive, as abordagens que a consideram como ações de caráter informativo sobre os alimentos, com predomínio de uma concepção do aprender a comer.

Os escolares de 1a a 3a séries relataram não saber sehavia diferença quanto ao tipo decultivo dos alimentos utilizados nas refeições da escola, bem como não tinham noção sobre o que seria alimento orgânico. Já os escolares das séries mais avançadas destacaram que 0 assunto foi abordado na disciplina de Ciências e que o diferencial deste tipo de alimento estava no tipo de cultivo. Além disso, mesmo sabendo que há diferenças no tipo de alimentos utilizados na alimentação da escola, não sabem quando se trata do produto orgânico nas refeições servidas. Lima ${ }^{36}$, em sua 
pesquisa nesta escola, concluiu haver dificuldades por parte dos escolares em traduzir o que são alimentos orgânicos, relacionando-os aos vegetais produzidos na horta escolar.

Os escolares das séries iniciais, além de se expressarem melhor através do desenho, tiveram maior facilidade em relatar o quegostavam e não gostavam no momento da alimentação na escola e que alimentos consumiam mais:

[Desenho] É um boneco comendo a maçã, que faz bem pra todo mundo.

Tem fruta e verdura na escola, maçã, alface, mas pouca variação. face.

Tem alface, banana, beterraba. Eu gosto de al-

Ressalta-se que, neste grupo, mais escolares referiram consumir a alimentação escolar durante a semana. Possivelmente este grupo, conforme as conclusões do estudo de Davanço et al. ${ }^{4}$, por ser formado por crianças de menor idade, ainda não tenha sofrido grandes interferências da mídia e outros meios, que não a escola e a família, em seus hábitos alimentares. Desta forma, destaca-seo papel da escola, colaborando para construção e desenvolvimento da consciência crítica dos pais e dos próprios escolares acerca de suas preferências e escolhas alimentares ${ }^{4,32}$. M ainardi ${ }^{17}$ observa que os alunos consideram a família como principal formadora de seus hábitos alimentares. A Portaria Interministerial do Ministério da Saúde e Educação ${ }^{13}$ enfatiza a corresponsabilidadeeimportância das famílias no processo de alcance de uma alimentação saudável no ambiente escolar.

Os escolares das 4a a 7ạ séries eram, em maioria, adolescentes e as críticas e observações escritas e verbais sobre a alimentação escolar oferecida surgiram com mais ênfase. A maioria deste grupo come a refeição eventualmente e declara fazê-lo apenas quando o tipo de alimento ou preparação Ihes apetece. Sturion et al. ${ }^{20}$, avaliando fatores condicionantes da adesão ao Programa deAlimentação Escolar de escolas públicas, reve laram que, quanto maior a idade, menor a frequência de consumo da alimentação escolar durante a semana. Por tratar-se de uma fase de mudanças psicoafetivas, o comportamento al imentar dos adolescentes pode sofrer modificações.

Os dois grupos de escolares referiram a qualidade e quantidade dos alimentos servidos, as condições de serviço e a forma como as merendeiras preparam a comida ofertada: A merenda às vezes éboa. Tem gentequeacha todo dia gostoso. Podia melhorar a quantidade de carne, a oferta de suco.
A comida é normal. Comida boa, de restaurante

A [nome da merendeira], ela cozinha bem.

A [nome da merendeira] faz com capricho, é bom.

A [nome da merendeira] cozinha [período de trabalho] e de vez enquanto é ruim.

$\mathrm{N}$ ão tem copo no bebedouro.

$\mathrm{Na}$ escola, atualmente, as refeições são oferecidas em balcão térmico e os alunos podem se servir das preparaç̧ões. Esta condição foi considerada pelos grupos como muito importante, conferindo-os certa autonomia quanto à quantidade e tipo de preparação que querem consumir.

Outro aspecto relatado foi a importância da alimentação oferecida na escola. Os escolares relacionam a alimentação da escola com uma alimentação equilibrada, favorecedora de seu bom crescimento edesenvolvimento físico e, além disso, supridora de energia durante o período em que permanecem na instituição:

A comida éimportante porque ajuda no nosso desenvolvimento. Tem criança que não tem o que comer em casa, daí ela comena escola, éimportante por isso.

Como a merenda porque é saudável e dá energia.

Feijão e arroz para dar mais energia, para ficar bem alimentado, para crescer bem forte.

E mata a minha fome.

Tendo em vista os aspectos apontados e considerando a escola como um espaço de convivência dos escolares, torna-se imperativo o desenvolvimento de atividades educacionais em saúde, alimentação e nutrição que fomentem 0 interesse ea curiosidade ${ }^{4}$, o incentivo ao exercício permanente de direitos e deveres, superando 0 caráter assistencialista da alimentação ${ }^{35}$. Como exemplo, ações quefavoreçam a partici pação dos escolares no processo de transformação do ambiente (pintura e decoração do refeitório, elaboração de painéis informativos e manutenção da horta) parecem ser al gumas das alternativas para contribuir com a formação crítica sobre as formas de condução de sua saúde.

A iniciativa das Escolas Promotoras de Saúde ${ }^{6}$ pressupõe que, ao adquirir e construir conhecimentos sobre saúde, a criança e o jovem adquirem valores, habilidades, destrezas e práticas necessárias para uma vida saudável. Neste processo, se contrai a capacidade de formar e fortalecer comportamentos e hábitos saudáveis. Salienta-se ainda que a introdução do tema alimentação/alimentos orgânicos nesta escola pode servir como norteador dentro do projeto políti- 
co pedagógico para a discussão edesenvolvimento dos temas transversais ${ }^{11}$ propostos pelo $\mathrm{Mi}$ nistério da Educação.

\section{Consideraçõesfinais}

A pesquisatevecomo objetivo diagnosticar as ações de educação em saúde e nutrição com base na alimentação orgânica em uma escola pública estadual em Santa Catarina, envolvendo a gerência da alimentação escolar, direção da escola, professores eescolares. Os resultados da pesquisa permitiram o levantamento dos seguintes elementos:

- As reformulações do Programa Nacional de Alimentação Escolar têm avançado em seus objetivos, com recomendações acerca da necessidade de estímulo de hábitos alimentares saudáveis no âmbito escolar;

. Em Santa Catarina, a utilização dos produtos de origem orgânica na alimentação escolar pode ser considerada um avanço em direção à melhoria da qualidade de vida dos estudantes catarinenses e produtores locais de alimentos orgânicos. No entanto, a avaliação de indicadores educacionais, sociais e de saúde dos escolares, preconizados pelo Projeto Sabor Saber, não vem sendo realizada;

- No projeto político pedagógico (PPP), os temas saúde, alimentação e nutrição são apontados em al gumas disciplinas, porém não há transversalidade destes temas. Este conteúdo é abordado principalmente pela disciplina de Ciências;

- A alimentação orgânica na escola é apontada como um diferencial pelos professores, que referem a constante informação aos escolares. No entanto, há dificuldade de organização de ações pedagógicas que ultrapassem a informalidade dos temas alimentação e nutrição. A neces- sidade de formação para os professores sobre alimentos orgânicos é referida pela direção da escola;

- Os escolares avaliam de forma positiva a alimentação da escola, destacando aspectos como saúde e equilíbrio, a quantidade, o tipo de serviço, o preparo e o trabalho das merendeiras. Eles sabem que a alimentação escolar tem um diferencial, principalmente pela oferta de verduras, frutas, arroz, feijão, mas não fazem referência ao uso de produtos de origem orgânica;

- 0 desenvolvimento da técnica de gruposfocais com os professores possibilitou a reflexão para o planejamento de novas ações envolvendo osalimentos orgânicosededar continuidadeàquelas já instituídas como ações com a horta escolar, mercado em sala de aula e a feira de ciências.

A partir dos resultados deste estudo, enfatiza-se a relevância da implementação de ações de educação em saúde em nutrição, aproveitandose o contexto de utilização do alimento orgânico na escola. Estas ações podem vir a colaborar com a compreensão da cadeia produtiva que envolve o alimento orgânico, promovendo-se na escola a discussão dos aspectos sociais de projetos que visem à manutenção de agricultores agroecológicos em seus locais de origem, assim como a val orização de seus hábitos e costumes, a preservação da cultura local, os aspectos referentes à conservação do meio ambiente, conjugando estas discussões com a temática da saúde, alimentação e nutrição.

Destaca-se ainda que, diante dos propósitos do Projeto Sabor e Saber, torna-se relevante a continuidade de parcerias entre os produtores orgânicos, a direção das escolas atendidas e gestores estaduais da educação para a sensibilização dos gestores federais, a fim de atender às legislações referentes ao tema.

\section{Colaboradores}

E Cunha trabalhou em todas as etapas da pesquisa, desde a concepção do projeto e coleta de dados até a elaboração do artigo. AA Sousa orientou todas as etapas da pesquisa, na idealização do artigo, na análise da pesquisa e revisão do texto final. NM V M achado orientou o delineamento metodológico. 


\section{Referências}

1. Brasil. Ministério da Educação. Programa Nacional de Alimentação Escolar. Brasília: Fundo Nacional de Desenvolvimento da Educação; 2004.

2. Zitkioski JJ. Horizontes da (Re) fundamentação da Educação Popular: um diálogo entre Freire e Habermas. Frederico Westphalen: Editora Uri; 2000.

3. Costa EQ, Ribeiro VM B, Ribeiro ECO. Programa de alimentação escolar: espaço de aprendizagem e produção de conhecimento. Rev. Nutr. 2001; 14(3):225-229.

4. Davanço GM, Taddei JAC, Gaglianone CP, Colugnati FAB. Hábitos alimentares de escolares $\left(1^{\text {as }}\right.$ e 2 as séries) durante a merenda escolar em escolas públicas de São Paulo, SP. Rev Paul Ped. 2004; 22(2):95101.

5. Aerts D, Alves GG, La Salvia MW, Abegg C. Promoção de saúde: a convergência entre as propostas da vigilância da saúde e da escola cidadã. Cad Saude Publica 2004; 20(4):1020-1028.

6. Brasil. M inistério da Saúde. Escolas promotoras de saúde: experiências do Brasil. Brasília: Ministério da Saúde/Organização Pan-Americana da Saúde; 2006.

7. Secretaria de Estado da Educação, Ciência e Tecnologia/Gerência de Merenda Escolar. M anual de O peracionalização do Programa de Alimentação Escolar Orgânica. Florianópolis: SED/Gerência de M erenda Escolar; 2003.

8. Brasil. Lei $n^{\circ} 10.831$ de 24 de dezembro de 2003 Dispõe sobre a agricultura orgânica e dá outras providências. Diário Oficial da U nião 2003; 24 dez.

9. Ormond JGP, Paula SRL, Faveret Filho P, Rocha LTM . Agricultura Orgânica: quando o passado é futuro. BNDES setorial 2002; 15:3-34.

10. Altmann R, Oltramari AC. A agricultura orgânica na região da Grande Florianópolis; indicadores de desenvolvimento. Florianópolis: Instituto Cepa; 2004.
11. Brasil. M inistério da Educação. Parâmetros Curriculares $\mathrm{N}$ acionais: meio ambiente, saúde. Brasília: Secretaria de Educação Fundamental; 1997.

12. Organização Mundial de Saúde. Estratégia global da O M S para Alimentação e Nutrição [tradução não oficial da 57ạ Assembléia M undial de Saúde] 2004 maio [acessado 2006 dez 03]; [cerca de 23 p.]. Disponível em: http://dtr2004.saude.gov.br/nutricao/ documentos/eb_portugues.pdf

13. Brasil. Portaria Interministerial no 1.010 de 8 de maio de 2006. Institui as diretrizes para a Promoção da Alimentação Saudável nas Escolas de educação infantil, fundamental e nível médio das redes públicas e privadas, em âmbito nacional. Diário Oficial da União 2006; 9 mai.

14. Triviños ANS. Introdução à pesquisa em ciências sociais: a pesquisa qualitativa em educação. São Paulo: Atlas; 1987.

15. M inayo M CS. Pesquisa social: teoria, método e criatividade. Petrópolis: Vozes; 2002.

16. Bezerra JAB. Comer na escola - significados e implicações [tese]. Fortaleza (CE): U niversidade Federal do Ceará; 2002.

17. M ainard N. A ingestão de alimentos e as orientações da escola sobre alimentação sob o ponto de vista do aluno concluinte do ensino fundamental [dissertação]. São Paulo (SP): Escola Superior de Agricultura Luiz de Queiroz/U niversidade de São Paulo; 2005.

18. M agal hães AM. A horta como estratégia de educação alimentar em creches [dissertação]. Florianópolis (SC): U niversidade Federal de Santa Catarina; 2003.

19. Weigert C, Villani A, Freitas D. Interdisciplinaridade e o trabalho coletivo: análise de um planejamento interdisciplinar. Ciência \& Educação 2005; 11(1):145-164. 
20. Sturion GL, Silva M V, O metto AM H, Furtuoso M CO, Pipitone MAP. Fatores condicionantes da adesão dos alunos ao Programa de Alimentação Escolar no Brasil. Rev Nutr. 2005; 18(2):167-181.

21. Mogilka M. A formação humana no horizonte da integralidade. Rev Bras Est Pedag 2006; 87(215):5367.

22. Quivy R, Campenhoudt L. M anual de investigação em ciências sociais. Lisboa: Gradiva; 2005.

23. M inayo M CS. 0 desafio do conhecimento: pesquisa qualitativa em saúde. São Paulo: Hucitec; Rio de Janeiro: Abrasco; 2006.

24. Kind L. Notas para o trabalho com a técnica de grupos focais. Psicol rev. 2004; 10(15):124-136.

25. Imianowski S. Percepções de crianças em idade escolar sobre saúde, por meio da interpretação do desenho infantil [dissertação]. São Paulo (SP): Faculdade de Saúde Pública; 2001.

26. Bardin L. Análise de Conteúdo. Lisboa: Edições 70; 2006.

27. Brasil. Resolução FNDE $n^{\circ} 32$ de 10 de agosto de 2006. Estabelece as normas para execução do Programa Nacional de Alimentação. Brasília: Fundo Nacional de Desenvolvimento da Educação; 2006.

28. Secretaria de Estado da Educação, Ciência e Tecnologia/Gerência de Merenda Escolar. Programa Estadual de Alimentação Escolar - PEAE. Florianópolis: SED/Gerência de M erenda Escolar; 2006.

29. Ribeiro OM. E se Narciso conhecesse Alice? Conjecturas a respeito de um tema da educação. Rev Bras Est Pedag. 2006; 87(215):53-67.

30. Monfredini 10. 0 projeto pedagógico em escolas municipais: análise da relação entre a autonomia e manutenção e/ou modificação de práticas escolares. Educ Pesqui. 2002; 28(2):41-56.
31. Neto AC, Almeida MD. Educação e gestão descentralizada: conselho diretor, caixa escolar, projeto político-pedagógico. Em aberto 2000; 17(72):1-195.

32. Santos LAS. Educação alimentar e nutricional no contexto da promoção de práticas alimentares saudáveis. Rev Nutr. 2005; 18(5):681-692.

33. Davanço GM, Taddei JAAC, Gaglianone CP. Conhecimentos, atitudes e práticas de professores de ciclo básico, expostos e não expostos a Curso de Educação Nutricional. Rev Nutr. 2004; 17(2):177184.

34. Gaglianone CP, Taddei JAC, Colugnati FAB, MagaIhães $C G$, Davanço $G M, M$ acedo $L$, Lopez FA. Educação nutricional no ensino público fundamental em São Paulo, Brasil: projeto redução dos riscos de adoecer e morrer na maturidade. Rev. Nutr 2006; 19(3):309-320.

35. Ferreira VA, Magalhães R. Nutrição e promoção da saúde: perspectivas atuais. Cad Saúde Publica 2007; 23 (7):1674-1681.

36. Lima EE. Os alimentos orgânicos na alimentação escolar pública catarinense: um estudo de caso [dissertação]. Florianópolis (SC): Universidade Federal de Santa Catarina; 2006.

Artigo apresentado em 28/07/2007

Aprovado em 17/09/2007

Versão final apresentada em 15/10/2007 